\title{
Remote Water Quality Monitoring with Early -Warning System for Marine Aquaculture
}

\author{
Rozeff Pramana ${ }^{1,2}$, Bhakti Yudho Suprapto ${ }^{1}$, Zainuddin Nawawi ${ }^{* 1}$ \\ ${ }^{1}$ Department of Electrical Engineering, Faculty of Engineering, Universitas Sriwijaya, Jl. Raya Palembang Prabumulih, KM.32, \\ Indralaya, Indonesia \\ ${ }^{2}$ Department of Electrical Engineering, Faculty of Engineering, Universitas Maritim Raja Ali Haji, Kampus Senggarang 29111, \\ Tanjungpinang, Indonesia
}

\begin{abstract}
Rapid technological developments have penetrated the application of technology in the field of aquaculture. Climate Changes that are currently uncertain and beyond prediction encourage the application of technology to increase fishery production and modernization. The purpose of this study is to design a water quality monitoring system that can be monitored remotely in real-time using an internet-based smartphone/PC application. It is equipped with an early warning system to monitor the water quality set by the upper and lower thresholds. This device is based on Robotdyn Uno Wifi R3 ESP8266 with IoT technology. The alarm system uses a buzzer and LED indicator to make it understandable to fishermen. We tested the device in two stages. Results showed that the alarm system responds to all changes in water quality that exceeds the set threshold. Water quality data can be monitored with an internet-based smartphone application and updated every 15-16 seconds
\end{abstract}

\section{Introduction}

The use of technology has been widely implemented in various aquaculture activities. The current research themes are the use of sensors, water quality monitoring, control systems, remote monitoring, fish cage design, and the use of water vehicles to support aquaculture activities. Rapid technological developments and climate change have triggered these developments. Climate change grows as a significant threat to marine biodiversity that will impact fishery production, both saltwater and freshwater fisheries [1], [2]. The utilization of technology can be a solution to overcome these problems.

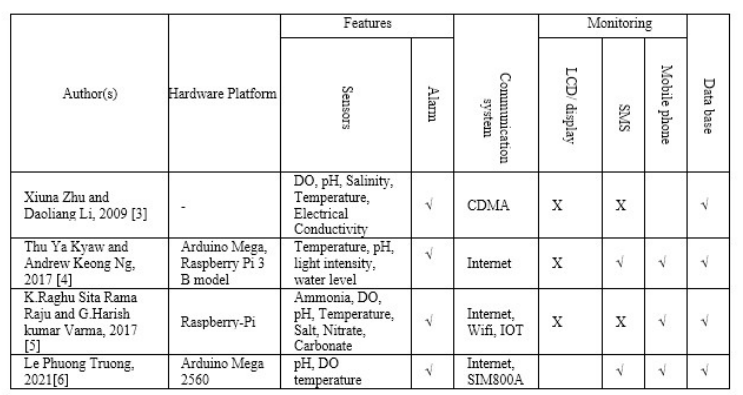

Table 1. Research on the application of alarm systems in aquaculture.

Research on early warning or alarm systems in aquaculture uses email, SMS, and applications through various communication media [3]-[6]. Many studies have been carried out in developing water quality sensors, heaters, aerators, pumps, reservoirs, water levels [7]-[12]. The use of feeders has also been developed with various techniques [1], [13]-[17]. And, the development of aquaculture technology has also involved the use of cameras [18], [19], and sensor cleaning feature to optimize sensor readings [20]. This paper proposes a water quality monitoring system in fish cages with an early warning system with upper and lower thresholds. This device is based on Robotdyn Uno Wifi R3 ESP8266 with IoT technology. The alarm system uses a buzzer and LED indicator to make it easier to warn fishermen.

System Architecture, This device consists of a sensor system, a data processing unit, a monitoring/database system, a wireless communication system, an alarm system, and a resource unit, as shown in Figure 1.

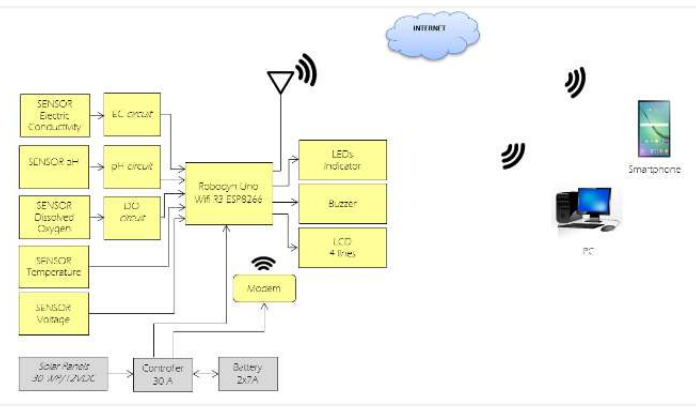

Figure. 1. Design Diagram

\footnotetext{
* Corresponding author: nawawi_z@yahoo.com
} 
Sensors System; The sensors consist of Electric Conductivity (EC), pH, Dissolved Oxygen (DO), and DS18B20 temperature sensors. The EC, $\mathrm{pH}$, and DO sensors are analog sensors from the same manufacturer (DFRobot). These sensors function as input devices that change the amount of water quality into electrical quantities. The reading of the water quality sensor values in water is used as data that the user can monitor remotely. In addition to the four water quality sensors, there is also a voltage sensor that informs the battery voltage value, which is the energy source of the device. All of these sensors are connected to the input of the data processing unit.

Data Processing Unit; The data processing unit used is a Robotdyn Uno Wifi R3 ESP8266. This device is equipped with Wifi and antenna features. This data processing unit processes data received from input devices, namely all sensors and other input devices. The software used for programming is the Arduino IDE. The information signal from the reading of each sensor will then be processed by the data processing unit so that it can be sent and read by the user. The data processing unit is also connected to the output of this device, namely the LED indicator, buzzer, and LCD. The upper threshold value and the lower threshold value for alarm system purposes are set in this device. The operating voltage used for this device is 12 VDC sourced from the available solar panels.

Monitoring system and database, The monitoring system serves to display data from each sensor. The monitoring unit consists of an LCD and the Thingspeak application. The LCD used is a 4-line LCD type, which shows water quality reading values in real-time. The Thingspeak application functions as an application that displays data of the water quality sensor and voltage sensor values in graphs on a real-time basis. The application can be used via a smartphone or PC connected to the internet network to access remotely. This device is also equipped with a database that can store data on the complete reading parameters of each sensor.

Wireless communication system; The wireless communication system designed consists of a Wifi module, an antenna, and a modem. This wireless communication system functions as a medium for sending sensor reading data so that users can receive it from remote locations. The communication network used in this study is a $4 \mathrm{G}$ cellular network. The modem used is the Mifi Huawei E5573BOLT 4G LTE Modem. Meanwhile, Wifi has been integrated with the data processing device used by Robotdyn Uno Wifi R3 ESP8266.

Alarm system; The alarm unit consists of a LED and a buzzer: four blue LEDs, four red LEDs, and one buzzer. This unit functions to warn users if the water quality exceeds the upper or the lower thresholds. If the water quality exceeds the upper threshold, the indicator is red, and if it exceeds the lower threshold, the indicator is blue. Meanwhile, if there is no LED light, it indicates the water quality is in normal condition. Threshold values for each sensor EC, $\mathrm{pH}, \mathrm{DO}$, and temperature are determined and programmed into the system. These values should be adjusted to the normal habitat of the species being cultivated in the cages. The design of the alarm system is shown in Figure 2.

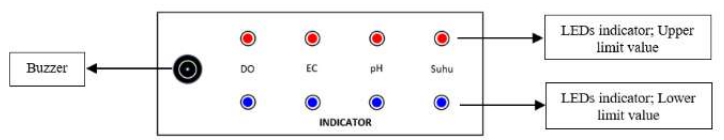

Figure 2. Design of alarm system

The power source to supply the power requirements for the operation of this device is a solar panel with an off-grid system. The power source unit used consists of one polycrystalline solar panel unit with a capacity of 30 WP 12 VDC, a 30 A controller, and two batteries with 7A/12 VDC each. Solar panels are placed horizontally with the direction of the cell facing up (the sun). System Implementation; The results of the device design are shown in Figure 3. Each assembled EC, pH, and DO sensor was calibrated using the available buffer liquid in the device. The reading value of the sensor on the LCD must be the same as or close to the value of the buffer liquid used for calibration. Furthermore, the device is integrated with other hardware such as LCD, LED indicator, and buzzer according to the design diagram in Figure 1.
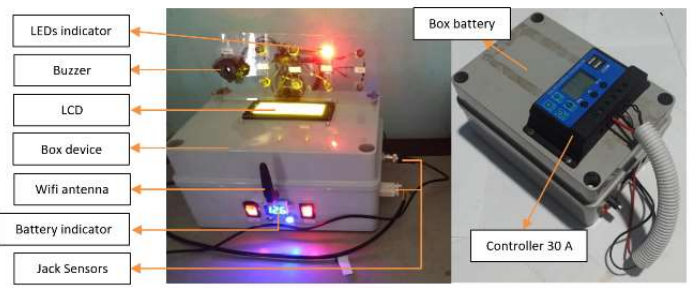

Figure 3. Remote water quality monitoring device with alarm system.

The upper and lower threshold values for the alarm system follow the Table 2 conditions:

\begin{tabular}{|l|c|c|c|}
\hline $\begin{array}{c}\text { Water } \\
\text { parameter }\end{array}$ & Unit & $\begin{array}{c}\text { Lower } \\
\text { threshol } \\
\text { d value }\end{array}$ & $\begin{array}{c}\text { Upper } \\
\text { threshold } \\
\text { value }\end{array}$ \\
\hline Temperature & ${ }^{\circ} \mathrm{C}$ & 24 & 30 \\
\hline $\mathrm{pH}$ & & 6.5 & 8.5 \\
\hline $\begin{array}{l}\text { Electric } \\
\text { Conductivity }\end{array}$ & $\mathrm{ms} / \mathrm{cm}$ & 15 & 50 \\
\hline $\begin{array}{l}\text { Dissolved } \\
\text { Oxygen }\end{array}$ & $\mathrm{ug} / \mathrm{L}$ & 4000 & 8000 \\
\hline
\end{tabular}

Table 2. Default of water quality values for the device alarm system.

Testing is carried out to ensure the device works as intended for this study. Device performance testing is carried out in two stages. The first stage of testing is delivered on the aquarium by placing all water quality sensors into an aquarium that has been filled with fresh water. In this test, a possible scenario of abnormal water quality conditions in the aquarium is simulated to trigger an active alarm, namely the buzzer sounds, and the LED indicator lights up. For example, if the aquarium water is given hot water beyond the set upper threshold value 
( $>30$ 0C), the buzzer will sound, and the red temperature sensor indicator will light. This indicates the water temperature value is above the highest threshold set by the system.

Furthermore, the aquarium water is given cold water until the temperature reaches $24-30^{\circ} \mathrm{C}$. As a result,the buzzer does not sound, and the LED temperature sensor indicator light does not turn on. This indicates the value of the water temperature under normal conditions. The aquarium is given cold water in the next test until it exceeds the set lower threshold value $\left(<24^{\circ} \mathrm{C}\right)$. As a result, the buzzer will sound, and the blue temperature sensor indicator LED will light up. This indicates that the water temperature value is below the lowest threshold set by the system. The same test was also carried out on other water quality sensors according to the parameters of each sensor. In the test, it is necessary to ensure that the buzzer sounds when one or more sensor indicator LEDs exceeds the set threshold, as shown in Figure 4. The device is operated using a $2 \times 7$ A battery without connecting to a solar panel in this first testing stage. The test is carried out until the device is inactive because it runs out of energy from the battery.

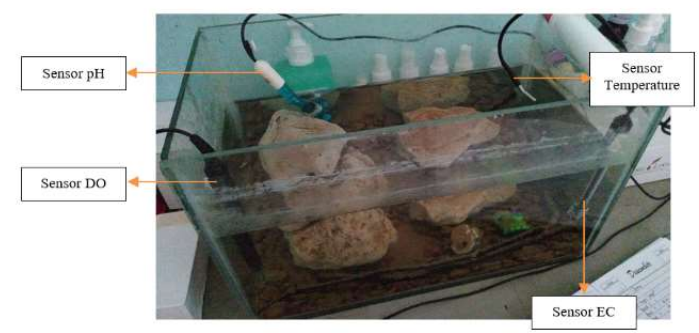

Figure 4. First stage experiment (aquarium)

The second testing stage was carried out at the actual location, in a fixed net cage located in Benan Island, Indonesia. The test location was chosen to be on the coast and close to densely populated settlements to get various changes in water quality. The seawater depth at the location reaches $2-2.5$ meters, seabed in mud and sand. Checking sensors, components, monitoring applications, and supporting devices must be implemented to ensure the devices are ready to operate in the actual location. In this phase, the sensor is placed at a $20-60 \mathrm{~cm}$ depth from sea level. Testings were employed for three days continuously to get an overview of device performance. Each stage of device testing is evaluated and analyzed.

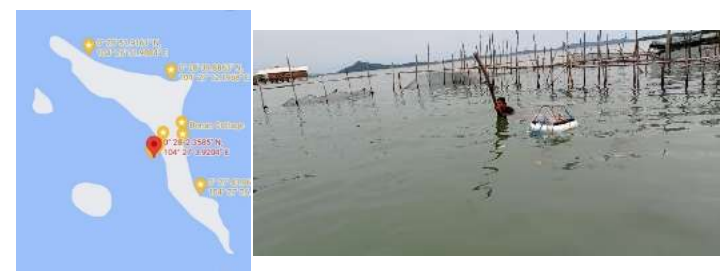

Figure 5. Second stage experiment (on-site)

\section{Result and Discussion}

\subsection{Monitoring System and Database}

Water parameter data measured by the EC, pH, DO, temperature, and voltage sensors are displayed on the LCD and the Thingspeak application. The LCD displays numeric data, while the Thingspeak application displays it in a graphical form. Data is presented in real-time with updates every 15-16 seconds. Users can see water quality data and battery indicators directly at the cage location on the installed device. In contrast, users far from the cage location can use a smartphone/PC to monitor water quality through the Thingspeak application. The user easily understands the data displayed on both the LCD and the application, with the units of each parameter being measured. The display of the device monitoring system can be seen in Figures 6 and 7.

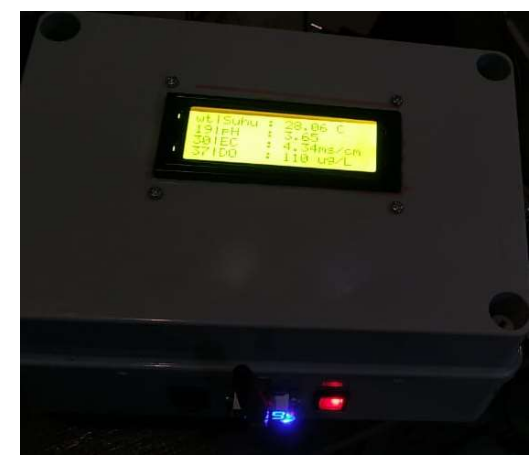

Figure. 6. Display of water quality and battery voltage monitoring on the LCD.
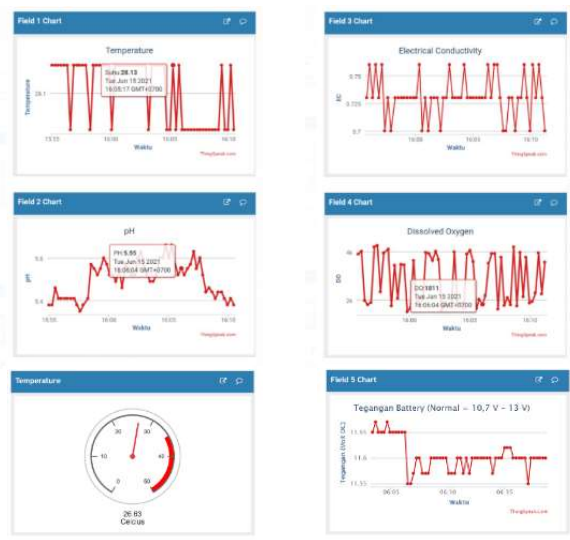

Figure. 7. Display of water quality and battery voltage monitoring on a smartphone/PC.

All data on water quality and battery voltage read by the sensor will be stored as a database in the application. The data can be downloaded in JSON, $\mathrm{XML}$, and CSV formats and used for future analysis.

\subsection{Alarm System}

Phase 1 test, which is carried out intentionally, affects the condition of water quality to be abnormal. This test is set to determine the response of the alarm system and device performance in adapting the changes of water parameters around the sensor. Table 2 presents 
data on several conditions from the results of the first stage of testing 1 .

In the tests carried out, it can be observed that the alarm system will work triggered from the value of water quality. It happens when the test values exceed the upper and lower thresholds. When one or more parameters exceed the threshold value, it triggers the buzzer to sound. Moreover, the relevant quality parameter LED indicators will light up according to the data indication from the related sensor. The red LED indicates that the sensor data exceeds the upper threshold, while the blue indicates the lower. If the water quality is normal, the LED does not light up. The work of the alarm system adjusts changes in data from reading the values of all sensors.

\begin{tabular}{|c|c|c|c|c|c|c|c|c|c|c|c|}
\hline \multirow[t]{2}{*}{ No. } & \multirow[t]{2}{*}{ Date/ time } & \multirow{2}{*}{$\begin{array}{l}\text { Tempe } \\
\text { rature } \\
\text { (C) }\end{array}$} & \multirow[t]{2}{*}{$\mathrm{pH}$} & \multirow{2}{*}{$\underset{(\mathrm{ms} / \mathrm{cm})}{\mathrm{EC}}$} & \multirow{2}{*}{$\begin{array}{c}\text { DO } \\
(\mu \mathrm{g} / \mathrm{L})\end{array}$} & \multirow{2}{*}{$\begin{array}{c}\begin{array}{c}\text { Battery } \\
\text { (Volt) }\end{array} \\
\end{array}$} & \multicolumn{5}{|c|}{ Alarm Status } \\
\hline & & & & & & & Buzz & L & D Ind & $\begin{array}{l}\text { icator } \\
\text { FC }\end{array}$ & 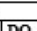 \\
\hline 1 & $\begin{array}{c}2021-08-05 \\
16: 44: 31\end{array}$ & 28,06 & 7,2 & 0,28 & 4788 & 12,28 & $\mathrm{On}_{n}$ & & & - & \\
\hline 2 & $\begin{array}{c}2021-08-05 \\
16: 44: 46\end{array}$ & 28,06 & 6,9 & 0,25 & 5347 & 12,28 & On & & & - & \\
\hline 3 & $\begin{array}{c}2021-08-05 \\
16: 45: 02\end{array}$ & 28 & 6,81 & 0,23 & 4925 & 12,28 & $\mathrm{On}_{n}$ & & & - & \\
\hline 4 & $\begin{array}{c}\text { WIB } \\
16: 08-05 \\
16: 45: 17 \\
\text { WIB }\end{array}$ & 28 & 6,81 & 0,25 & 4141 & 12,26 & $\mathrm{On}_{\mathrm{n}}$ & & & • & \\
\hline 5 & $\begin{array}{c}2021: 08-05 \\
16: 45: 33 \\
\text { WIB }\end{array}$ & 27,94 & 6,84 & 0,25 & 4723 & 12,26 & On & & & - & \\
\hline 6 & $\begin{array}{c}2021-08-05 \\
16: 45.48 \\
\text { WB }\end{array}$ & 27,94 & 6,65 & 0,25 & 4861 & 12,28 & On & & & - & \\
\hline 7 & $\begin{array}{c}2021: 08-05 \\
16: 46: 04 \\
\text { WIB }\end{array}$ & 27,88 & 6,76 & 0,25 & 4652 & 12,26 & On & & & • & \\
\hline 8 & $\begin{array}{c}2021-08-05 \\
16: 46: 19\end{array}$ & 27,88 & 6,7 & 0,25 & 4652 & 12,28 & $\mathrm{On}_{n}$ & & & • & \\
\hline 9 & $\begin{array}{c}2021-08-05 \\
16: 46: 35\end{array}$ & 27,81 & 6,73 & 0,25 & 4766 & 12,28 & On & & & • & \\
\hline 10 & $\begin{array}{c}2021-08-05 \\
16: 47: 38\end{array}$ & 27,88 & 6,54 & 0,25 & 4675 & 12,26 & On & & & • & \\
\hline 11 & 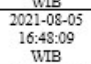 & 27,81 & 6,57 & 0,23 & 4675 & 12,26 & On & & & - & \\
\hline 12 & $\begin{array}{c}2021-08-06 \\
15: 00.01 \\
\text { WIB }\end{array}$ & 32,13 & 0,84 & 18,36 & 12131 & 11,74 & On & $\bullet$ & - & & $\bullet$ \\
\hline 13 & $\begin{array}{c}2021-08-06 \\
15: 01: 03 \\
\text { WIB }\end{array}$ & 32,13 & 0,82 & 18,36 & 12131 & 11,77 & On & $\bullet$ & - & & $\bullet$ \\
\hline 14 & $\begin{array}{c}2021-08-06 \\
15: 03: 07\end{array}$ & 32,13 & 0,84 & 18,44 & 12131 & 11,74 & On & $\bullet$ & - & & $\bullet$ \\
\hline 15 & $\begin{array}{c}2021-08-06 \\
15: 05: 12 \\
\text { WMB }\end{array}$ & 32,13 & 0,82 & 18,39 & 12131 & 11,77 & On & - & - & & $\bullet$ \\
\hline 16 & $\begin{array}{c}2021-08-06 \\
16: 52: 24\end{array}$ & 27,31 & 5,08 & 0,26 & 7330 & 11,4 & On & & • & • & \\
\hline 17 & $\begin{array}{c}2021-08-06 \\
16: 53: 26\end{array}$ & 27,31 & 4,91 & 0,26 & 5958 & 11,4 & On & & - & • & \\
\hline 18 & $\begin{array}{c}\text { W1B } \\
2021-08-06 \\
16: 54: 29 \\
\text { WIB }\end{array}$ & 27,38 & 4,86 & 0,26 & 4370 & 11,38 & On & & - & - & \\
\hline
\end{tabular}

Table 3. Result of first stage experiment (aquarium)

The alarm status on the alarm display (Figure 2) is always updated according to changes in the data. From Table 2 can be seen that the sensor reading data is updated every 15-16 seconds. The stage two test was carried out at an actual location in one of the coastal aquaculture cages. The location was chosen where the water quality changed rapidly to determine the response of the alarm system and the device's performance. Table 3 displays the test results of the device at the actual location.

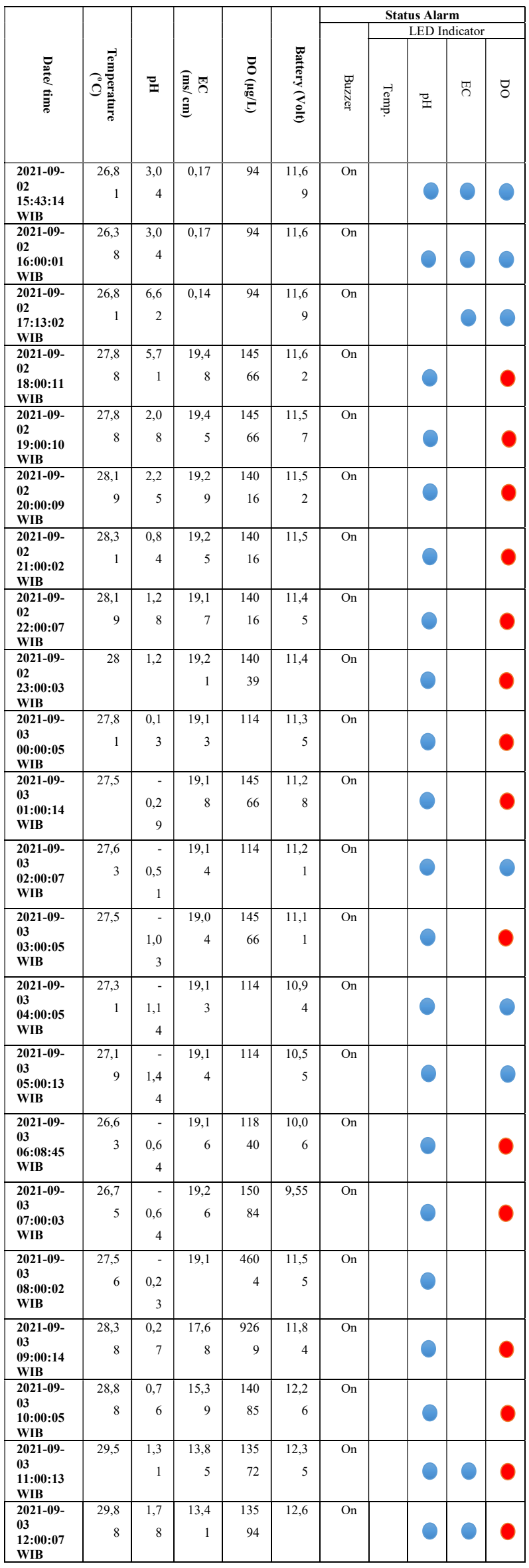




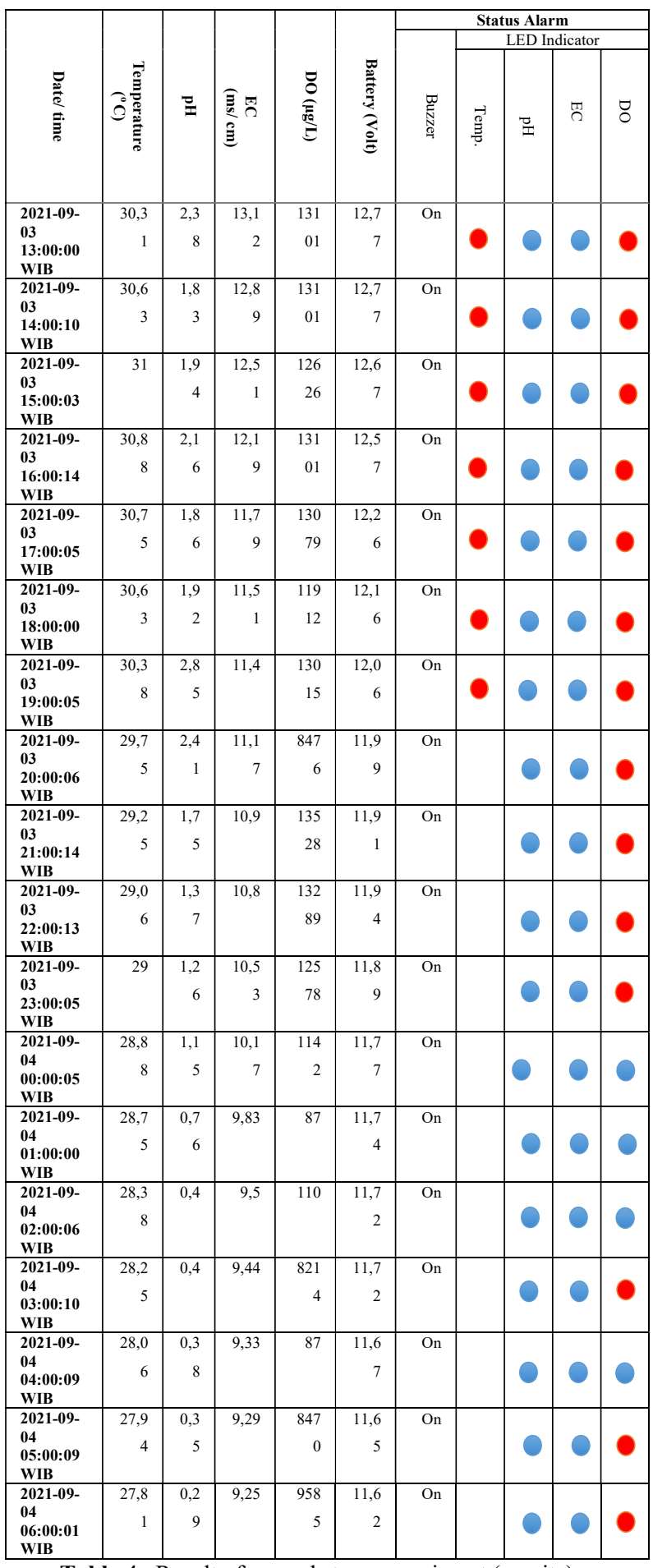

Table 4. Result of second stage experiment (on-site)

\subsection{Battery performance}

Battery performance testing is carried out by operating all systems, including cooling fans. The result of battery performance testing is shown in Figure 8 below:

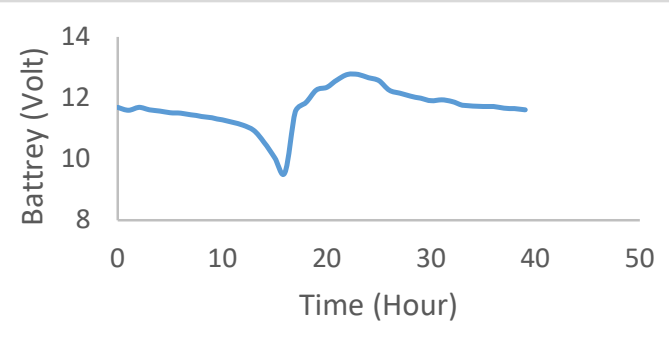

Figure. 8. Graph of battery change versus operating time

On the second day of testing, after operating for about 15 hours, the battery experienced a lack of energy with a drastic voltage drop. This event caused the device to stop operating at $05: 40: 55$ WIB (September 3, 2021) with the voltage listed in the 9.25 VDC database. This condition occurred because the weather around the test location was rainy and cloudy all day on the first day of testing (September 2, 2021), and the battery was not fully charged. The device is active again at 06:08:45 WIB when the solar panel unit of the device gets sunlight and stores electricity in the battery. On the second and third days (September 3 and 4, 2021), the weather around the test cages was sunny. This condition caused the solar panel to work optimally to save power to the battery. As a result, the device no longer experienced off-like testing as happened on the second day. Battery testing was also carried out without using solar panels, and the battery was fully charged, with results shown in Table 4 below:

\begin{tabular}{|c|c|c|c|}
\hline $\begin{array}{l}\text { Battery } \\
\text { Capacity }\end{array}$ & $\begin{array}{c}\text { Number } \\
\text { of } \\
\text { Batteries }\end{array}$ & $\begin{array}{c}\text { Operation } \\
\text { time } \\
\text { (minutes) }\end{array}$ & Description \\
\hline $7 \mathrm{~A}$ & 1 & 919 & $\begin{array}{c}15 \text { hours 19 } \\
\text { minutes }\end{array}$ \\
\hline 7A & 2 & 1422 & $\begin{array}{c}23 \text { hours 42 } \\
\text { minutes }\end{array}$ \\
\hline
\end{tabular}

Table 5. Battery performance

From the test results in Table 4, the device equipped with two batteries with a capacity of 7A can operate for 23 hours and 42 minutes continuously without using a solar panel. This device itself operates 24 hours continuously every day with a solar panel energy source. This panel can use and store solar energy during the day and use it at night.

\subsection{Device performance}

The device operates to transmit data when it gets a good cellular network signal. The user cannot monitor the sensor data remotely if the cellular network signal around the cage is poor. However, the sensor reading data is still displayed on the monitoring device's LCD. Once activated and the device starts to work, the device system will work automatically and operate as long as battery energy is available. If the battery energy is insufficient, the device will turn off operating. The device will return to operation when the solar panel gets sunlight and charges the battery. 


\section{Conclusion}

The device operates to transmit data when it gets a good cellular network signal. Devices can be monitored remotely using internet-based applications via smartphones or PCs. Sensor reading data is updated every 15-16 seconds. The monitored data is real-time and equipped with a database and an alarm system to warn the water quality exceeds the specified threshold. The alarm system works as programmed with warnings in sounds (buzzers) and visual warnings (LEDs indicators). The device operates automatically from the first time it is activated. When the battery source is weak, the device will turn off and automatically resume operation when the battery gets electrical energy from the solar panel unit. The capacity of the $2 \times 7 \mathrm{~A}$ battery is capable of operating for 23 hours and 42 minutes without a solar panel energy source.

\section{References}

1. J. H. Chen, W. T. Sung, and G. Y. Lin, Proceedings - 2015 IEEE International Conference on Systems, Man, and Cybernetics, SMC 20151161 (2016).

2. M. M. Islam, N. Islam, A. Habib, and M. M. H. Mozumder, Sustainability (Switzerland) 12, 1 (2020).

3. Z. Xiuna and L. Daoliang, Proceedings - 2009 WRI International Conference on Communications and Mobile Computing, CMC 2009 2, 380 (2009).

4. T. Y. Kyaw and A. K. Ng, Energy Procedia 143, 342 (2017).

5. K. R. S. R. Raju and G. H. K. Varma, Proceedings - 7th IEEE International Advanced Computing Conference, IACC 2017318 (2017).

6. L. P. Truong, Sensors and Materials 33, 575 (2021).

7. Y. Chen, G. Hou, and J. Ou, Proceedings of the IEEE International Conference on Software Engineering and Service Sciences, ICSESS 439 (2014).

8. S. Kayalvizhi, R. G. Koushik, K. P. Vivek, and N. Venkata, Prasanth, International Journal of Advanced Research in Electrical, Electronics and Instrumentation Engineering 4, 4554 (2015).

9. C. M. Fourie, D. V. Bhatt, B. J. Silva, A. Kumar, and G. P. Hancke, IEEE International Symposium on Industrial Electronics 2021 (2017).

10. A. D. M. Africa, J. C. C. A. Aguilar, C. M. S. Lim, P. A. A. Pacheco, and S. E. C. Rodrin, HNICEM 2017 - 9th International Conference on Humanoid, Nanotechnology, Information Technology, Communication and Control, Environment and Management 2018-Janua, 1 (2017).

11. Z. Harun, E. Reda, and H. Hashim, IOP Conference Series: Materials Science and Engineering 340, (2018).

12. T. Abinaya, J. Ishwarya, and M. Maheswari, 2019 International Conference on Computer Communication and Informatics, ICCCI 20191 (2019).

13. B. Rahmat, T. A. Rachmanto, M. Waluyo, M. I. Afandi, H. Widyantara, and H. Harianto,
Proceedings - 2016 International Seminar on Application of Technology for Information and Communication, ISEMANTIC 2016142 (2017).

14. W. T. Sung, J. H. Chen, and S. J. Hsiao, 2017 IEEE International Conference on Systems, Man, and Cybernetics, SMC 2017 2017-Janua, 2986 (2017).

15. K. N. Hairol, R. Adnan, A. M. Samad, and F. Ahmat Ruslan, Proceedings - 2018 IEEE Conference on Systems, Process and Control, ICSPC 2018218 (2018).

16. Y. B. Lin and H. C. Tseng, IEEE Access 7, 35457 (2019).

17. M. H. Rohit, S. Barua, I. Akter, S. M. M. Karim, S. Akter, and M. M. Lutfe Elahi, 2019 28th IEEE International Conference on Robot and Human Interactive Communication, RO-MAN 2019 (2019).

18. Y. Kim, N. Lee, B. Kim, and K. Shin, Proceedings - 2018 International Symposium on Computer, Consumer and Control, IS3C 2018189 (2019).

19. S. Saha, R. H. Rajib, and S. Kabir, 2018 International Conference on Innovations in Science, Engineering and Technology, ICISET 2018201 (2018).

20. W. Yueting, L. Jiaming, Y. Long, L. Xiaoming, and L. Weiqi, IFAC-PapersOnLine 51, 359 (2018). 